Deisy de Freitas Lima Ventura ${ }^{1,2}$ Rachelle Amália Agostini Balbinot ${ }^{2,3}$

\title{
A APLICAÇÃO JUDICIAL DAS NORMAS DA ORGANIZAÇÃO MUNDIAL DA SAÚDE NO BRASIL: IN DUBIO PRO SALUTE
}

Legal enforcement of the World Health Organization norms in Brazil: in dubio pro salute principle

\footnotetext{
${ }^{1}$ Instituto de Relações Internacionais, Universidade de São Paulo. São Paulo/SP, Brasil. ${ }^{2}$ Núcleo de Pesquisa em Direito Sanitário, Universidade de São Paulo. São Paulo/SP, Brasil. ${ }^{3}$ Centro de Estudos e Pesquisas de Direito Sanitário. São Paulo/SP, Brasil.
}

Correspondência: Deisy de Freitas Lima Ventura. E-mail: deisyflv@gmail.com.

Recebido em: 14/09/2014. Aprovado em: 30/09/2014. 


\section{RESUMO}

A empresa Acumuladores Ajax Ltda., uma das maiores fabricantes de baterias automotivas do Brasil, violou ao longo das últimas décadas normas de segurança no trabalho, ambientais e sanitárias, promovendo a contaminação do ar e do solo em áreas residenciais próximas à sua fábrica, localizada no município de Bauru (SP). O chamando "caso Ajax" possui, além da esfera administrativa, ao menos três frentes judiciais: a cível, a trabalhista e a fiscal. O caso Ajax chegou ao Superior Tribunal de Justiça sob a forma de um recurso relativo à execução fiscal de uma multa aplicada à empresa. O acórdão daí resultante evoca, entre outros, um tema raramente discutido no meio jurídico brasileiro, qual seja o alcance do direito da Organização Mundial da Saúde (OMS) no Brasil. Em 2002, um inquérito epidemiológico indicou que 314 crianças residentes no entorno da fábrica apresentavam taxas de plumbemia (presença de chumbo no sangue) superiores às que a OMS considera "aceitável". A empresa argumentou que o padrão da OMS não encontra respaldo na legislação brasileira. $\mathrm{O}$ relator do processo, Ministro Herman Benjamin, afirmou que, na ausência ou na manifesta desatualização dos padrões brasileiros, a contaminação e o consequente dano se caracterizam quando se constata o desrespeito aos padrões de instituições internacionais das quais o Brasil seja membro ou partícipe, aplicando o princípio in dubio pro salute. Segundo o relator, é dever do juiz fazer prevalecer a norma que melhor assegure a saúde, seja ela branda ou dotada de sanção, seja ela internacional ou interna.

\section{Palavras-chave}

Direito Internacional; Organização Mundial da Saúde; Soft Law.

\section{ABSTRACT}

Acumuladores Ajax Ltd., one of the largest automotive battery manufacturing company in Brazil, violated environmental, health and labour safety laws the past decades, causing air and soil contamination in residential areas that is in the vicinity of the factory located in Bauru, São Paulo, Brazil. The Ajax judicial case will be investigated in at least three legal instances - civil, labor, and tax - in addition to the administrative level. The Ajax legal case reached the Brazilian Court of Appeals in the form of an appeal related to the tax enforcement of a fine applied to the company. The resulting court ruling evokes a topic rarely discussed in the Brazilian legal community: the scope of the World Health Organization (WHO) rulings in Brazil. In 2002, an epidemiological survey indicated that 314 children living in the vicinity of the factory presented plumbemia levels (existence of lead in blood) higher than those considered "acceptable" by the WHO. The company argued that the WHO standards are not enforced by the Brazilian law. The rapporteur of the case, Minister Herman Benjamin, stated that in the absence or manifest outdating of Brazilian standards, the contamination and the resulting damages are characterized by the disrespect for international institutions standards of which Brazil is a member or participant, applying the in dubio pro salute principle. According to the rapporteur, it is the duty of the judge to enforce the norm that best ensures public health using either mild rules or those enforced with national or international sanctions.

\section{Keywords}

International Law; Soft Law; World Health Organization. 


\section{EMENTA}

PROCESSUAL CIVIL E AMBIENTAL. EMBARGOS À EXECUÇÃO FISCAL. MULTA. INFRAÇÃO. LEGISLAÇÃO ESTADUAL. IMPOSSIBILIDADE DE REVOLVER FATOS E PROVAS. SÚMULA 7/STJ. NORMA LOCAL. SÚMULA 280/STF. 1. Cuida-se, na origem, de Embargos à Execução Fiscal proposta para a cobrança de multa por descumprimento de normas ambientais da Lei Estadual $10.083 / 1998$, consistindo a conduta sancionada em expor a população residente nas imediações da empresa à contaminação por chumbo. 2. As alegações genéricas sobre ofensa ao art. 535, II, do CPC não superam o óbice da Súmula 284/STF, aplicável por analogia. 3. Não se pode apreciar, em Recurso Especial, a contrariedade aos arts. 5 , II, XXXIV e LV, e 150, I, IV, LIV e XLV, da Constituição Federal, sob pena de usurpação da competência do STF. 4. É inviável analisar as questões debatidas no Recurso Especial, o qual busca afastar as premissas fáticas estabelecidas pelo acórdão recorrido. Aplicação da Súmula 7/STJ: “A pretensão de simples reexame de prova não enseja recurso especial”. Inexiste violação ao art. 333 do CPC. 5. Por fim, os dispositivos legais do Decreto Estadual 8.468/1978 não se enquadram no conceito de "lei federal" de que trata o art. 105, III, da Constituição Federal, razão pela qual incide na espécie o óbice da Súmula 280/STF: "Por ofensa a direito local não cabe recurso extraordinário". 6. Recurso Especial não provido. (SUPERIOR TRIBUNAL DE JUSTIÇA, RECURSO ESPECIAL N. 1.310.471 - SP, RELATOR: MINISTRO HERMAN BENJAMIN, DATA DE JULGAMENTO: 18/06/2013, SEGUNDA TURMA)

\section{A jurisprudência brasileira e o direito da saúde global}

Posto que toda decisão judicial deve relatar, ainda que sinteticamente, os fatos que deram origem ao processo, a jurisprudência constitui um fabuloso observatório da vida social. Marie-Angèle Hermitte a percebe como uma "comédia humana", escrita por gerações sucessivas de juízes, uma espécie de "Balzac sem começo nem fim"1. Para este efeito, o acórdão ora publicado constitui um aporte inestimável na medida em que reconhece, talvez pela primeira vez no âmbito do Superior Tribunal de Justiça (STJ), a segregação social que se opera por meio da repartição desigual dos efeitos da poluição, estabelecendo uma relação de causalidade entre a injustiça social e a injustiça ambiental. O Ministro Herman Benjamin, relator do caso, reafirma o papel do juiz diante da transformação de uma "multidão de excluídos sociais" em "párias ambientais" e seu dever constitucional de interpretar de forma ampla as normas que ensejam as obrigações das empresas, fazendo inclusive duas referências ao princípio da precaução, embora não as desenvolva.

${ }^{1}$ HERMITTE, Marie-Angèle. Le droit saisi au vif - Sciences, Technologie, formes de vie. Paris: Pétra, 2013. p.19. 
É justamente quanto ao que o relator chama de "duplo padrão de controle de substâncias tóxicas e perigosas", um para a "elite-minoria" capaz de se autoproteger e outro para a "esmagadora maioria da sociedade", que a sentença em apreço evoca um tema raramente discutido no meio jurídico brasileiro. Trata-se do alcance do direito da Organização Mundial da Saúde (OMS) no Brasil, onde a doutrina sobre as normas sanitárias de origem internacional é tão escassa quanto a jurisprudência. Buscando minimizar tal lacuna, decidimos fazer o presente comentário sob o enfoque internacionalista.

Nossa pesquisa da jurisprudência do Supremo Tribunal Federal ${ }^{2}$ (STF) revela que as referências às normas da OMS, além de pouco numerosas, são eminentemente alusivas, no sentido de que o objeto principal das decisões tomadas no âmbito do STF com respeito à OMS não é a interpretação ou a aplicação de uma norma da organização.

Esta conclusão deriva do estudo de 23 decisões, das quais 22 mencionam o que costuma ser chamado de soft law da $\mathrm{OMS}^{3}$ : padrões sanitários, definições, classificações, recomendações ou formas de reconhecimento, cuja força vinculante em relação aos Estados-Membros da organização é bastante variável e, por vezes, até inexistente. Não foram encontrados casos relativos à aplicação da normatividade clássica (hard law) da OMS, que se compõe de suas convenções (artigo 19 da Constituição da $\mathrm{OMS}^{4}$ ) e de seus regulamentos (artigo 21) - afeitos ao tradicional

\footnotetext{
${ }^{2} \mathrm{~A}$ coleta na base de dados do STF foi realizada pelas autoras em 8 de julho de 2014 com o descritor "Organização Mundial da Saúde", na modalidade "pesquisa avançada” e em todas as seções disponíveis (acórdãos, súmulas, decisões monocráticas, decisões da Presidência do STF, questões de ordem, repercussão geral e boletim informativo). Das 72 entradas resultantes da pesquisa, 49 foram descartadas por configurarem mera justaposição de palavras (organização + mundial + saúde). Entre as 23 entradas pertinentes, no sentido de que efetivamente se referiam à Organização Mundial da Saúde, o único acórdão data de 1976 e corresponde a um caso de enfiteuse em que a OMS foi parte (RE 83368/RJ) -não se tratando, portanto, de aplicação do direito da OMS, e sim do direito civil brasileiro.

3Entre as "decisões monocráticas", 15 foram consideradas pertinentes: duas delas mencionam a definição de saúde que figura no preâmbulo da Constituição da OMS, de 1946 (ambas as decisões no âmbito da ADPF 54/DF, datadas de 2004 e 2008); sete decisões referem-se à classificação da drogadição como doença, conforme a Classificação Internacional de Doenças (CID) emitida pela OMS (por exemplo, HC 103115/DF, de 2010); duas citam o reconhecimento da profissão de optometrista pela OMS (Al 607782, de 2008; e RE 614111/TO, de 2013). Também aparecem referências aos standards de contaminação por amianto (ADPF 109 MC/SP, de 2009); à recomendação da OMS para adoção de nomes genéricos de medicamentos (Al 733689/SP, de 2009); ao limite de densidade de potência total para instalação de antenas transmissoras recomendado pela OMS (ADI 2902/SP, de 2003); e à definição do transtorno de personalidade (ARE 777527/DF, de 2013). Quanto às “decisões presidenciais", três entradas foram consideradas pertinentes: uma referência aos critérios da OMS para diagnóstico de osteoporose severa (SS 3989, de 2010); a menção de que a Agência Nacional de Vigilância Sanitária (Anvisa) é reconhecida pela OMS (SL 228/CE, de 2008); e o número recomendado pela OMS de leitos de UTI por habitante (SL 228/CE, de 2008). Nos "boletins informativos", as quatro entradas pertinentes revelam referências à já mencionada CID (por exemplo, ADInMC 1646/PE, de 1997).

${ }^{4}$ WORLD HEALTH ORGANIZATION. Constitution of the World Health Organization. Disponivel em: < http:// www.who.int/governance/eb/who_constitution_en.pdf>. Acesso em: 06 mar. 2015.
} 
direito dos tratados internacionais -, inteiramente dependente do consentimento dos Estados como condição da obrigatoriedade das normas ${ }^{5}$.

Em matéria de impacto nas ordens jurídicas nacionais, a falta de poder coercitivo da soft law é compensada por uma larguíssima adesão dos Estados, entidades privadas, profissionais da saúde, meios de comunicação e organizações sociais ao seu conteúdo normativo. Tamanha porosidade, de impossível mensuração global, é um dos fatores que explicam a emergência da expressão "direito da saúde global" na literatura especializada. Tal ramo do direito internacional seria o vasto campo de estudo e prática tanto da hard law como da soft law, que envolve normas, processos e instituições ${ }^{6}$. Segundo essa vertente da literatura, pouco importa que alguns instrumentos normativos internacionais possam ser classificados tanto como direito quanto como mera governança, eis que os limites entre direito e governança são pouco claros: "o direito seria o aspecto maior da governança, mas os recursos da governança podem dar forma ao direito" " O aspecto que pretendemos destacar no acórdão em comento é justamente o alcance jurídico de um padrão da OMS.

\section{O "Caso Ajax"}

A empresa Acumuladores Ajax Ltda., uma das maiores fabricantes de baterias automotivas do $\mathrm{Brasil}^{8}$, doravante referida como Ajax, estabeleceu-se no município de Bauru (SP) em 1958, em uma área industrial às margens da Rodovia SP-225 cujo processo de urbanização acelerou-se de modo significativo desde então. A partir dos anos 1980, a ocorrência de doenças profissionais em trabalhadores expostos ao chumbo ensejou numerosos pedidos de fiscalização do funcionamento da fábrica, formulados pelo Sindicato dos Metalúrgicos de Bauru e por outras entidades $^{9}$. Ao longo de três décadas, a atuação de diversos órgãos públicos, entre eles a Companhia Estadual de Tecnologia Ambiental (Cetesb) e o Ministério Público do Trabalho (MPT), permitiu constatar, por diferentes meios, além do descumprimento de normas de segurança no trabalho, a contaminação do ar e do solo em

\footnotetext{
${ }^{5}$ Enquanto a vigência das convenções nas ordens jurídicas dos Estados-Membros da OMS depende dos respectivos procedimentos constitucionais de incorporação (opting-in), a vigência dos regulamentos é resultado de um mecanismo de opting-out. Isso significa que, transcorrido o prazo no qual um Estado-Membro pode objetar total ou parcialmente um regulamento, o silêncio estatal resulta na plena vigência dessa norma no respectivo território. A única convenção até então aprovada no âmbito da OMS com base no artigo 19 de sua Constituição é a Convenção-Quadro sobre Controle do Uso do Tabaco, de 2003 (promulgada no Brasil pelo Decreto n. 5.658, de 2 de setembro de 2006). Já as principais normas adotadas com base no artigo 21 da Constituição da OMS são o Regulamento Sanitário Internacional, atualizado em 2005, e o chamado Regulamento de Nomenclatura da OMS, de 1948, que institui a classificação internacional de doenças e causas de morte, com suas atualizações. ${ }^{6}$ GOSTIN, Lawrence. Global health law. Cambridge; Londres: Harvard University Press, 2014. p.59.

${ }^{7}$ Id. Ibid.

${ }^{8} \mathrm{Na}$ época, com exportações para mais de 15 países, segundo GREENPEACE. Crimes ambientais corporativos no Brasil. jun. 2002. p. 7. Disponível em: <http://www.greenpeace.org.br/toxicos/pdf/corporate_crimes_port.pdf>. Acesso em: 26 jul. 2014.

${ }^{9}$ ITANI, Alice et al. Debate em gestão integrada em saúde e meio ambiente: fatos emblemáticos. Interfacehs - Revista de Gestão Integrada e Saúde do Trabalho e Meio Ambiente, v. 3, n. 2, abr./ago. 2008.
} 
áreas residenciais próximas à fábrica, resultante da "irresponsabilidade no manuseio contínuo da fábrica, que não possuía licença ambiental e despejava dejetos tóxicos há anos sem o menor cuidado requerido pelas leis"10.

Em 2002, um conjunto de medidas judiciais e extrajudiciais contra a Ajax teve grande repercussão local, especialmente o inquérito epidemiológico realizado pelas secretarias da Saúde do Estado de São Paulo e do Município de Bauru, cujos resultados indicaram que 314 crianças residentes no entorno da fábrica possuíam taxas de plumbemia (presença de chumbo no sangue) superiores à "aceitável"11.

Nesse diapasão, a OMS recomenda como “aceitável” uma concentração de chumbo no sangue das crianças abaixo de $10 \mu \mathrm{g} / \mathrm{dl}$, do mesmo modo que os Centros de Controle e Prevenção de Doenças dos Estados Unidos (Centers for Disease Control and Prevention - CDC) ${ }^{12}$. A literatura médica indica significativas alterações neurocomportamentais em crianças como efeito da intoxicação por chumbo com níveis acima de $10 \mu \mathrm{g} / \mathrm{dl}$, em especial deficiências no desenvolvimento psicológico (como hiperatividade, agressividade e impulsividade) e intelectual (como dificuldades nos planos da cognição e da linguagem) ${ }^{13}$.

Por outro lado, há evidências da interação entre o nível de chumbo e o nível socioeconômico da pessoa contaminada ${ }^{14}$. No caso de Bauru, o mapeamento das principais características das 314 crianças contaminadas indicou que 70,2\% delas tinham o hábito de brincar na terra; que os índices eram mais elevados entre as crianças pardas e pretas, e também entre as que moravam em ruas não asfaltadas ${ }^{15}$. Adicione-se que, diante desse tipo de contaminação, as crianças são as mais vulneráveis: enquanto os adultos absorvem de $5 \%$ a $15 \%$ da ingestão de chumbo e usualmente retêm menos do que $5 \%$ do que foi absorvido, as crianças apresentam uma absorção superior à dos adultos, sendo descritas faixas de $40 \%$ a $50 \%$ de absorção e $32 \%$ de retenção ${ }^{16}$.

${ }^{10}$ SALOMÃO, Virgínia. Empresa ou imprensa vilã? Caso de contaminação por chumbo na cidade de Bauru reafirma antigas deficiências na responsabilidade social corporativa. In: CONGRESSO VIRTUAL DE COMUNICAÇÃO EMPRESARIAL, 1. 2004. p. 3. Disponível em: <http://www.comtexto.com.br>. Acesso em: 26 jul. 2014.

${ }^{11}$ PADULA, Niura et al. Intoxicação por chumbo e saúde infantil: ações intersetoriais para o enfrentamento da questão. Cad. Saúde Pública, Rio de Janeiro, v. 22, n. 1, jan. 2006.

${ }^{12}$ DASCANIO, Denise; VALLE, Tania Gracy Martins do. A associação entre variáveis sócio-demográficas e plumbemia em crianças. Paidéia, Ribeirão Preto, v. 18, n. 4, p. 542, dez. 2008.

${ }^{13}$ DASCANIO, Denise, Crianças e adolescentes com plumbemia: habilidades sociais, funcionamento intelectual e problemas de comportamento. Tese (Doutorado) - Programa de Pós-graduação em Psicologia - Centro de Educação, Universidade Federal de São Carlos, 2012.

${ }^{14}$ Id. Ibid.

${ }^{15}$ FREITAS, Clarice. Vigilância de população exposta a chumbo no município de Bauru - São Paulo: investigação de fatores de risco de exposição e avaliação da dinâmica institucional. Tese (Doutorado) - Programa de Pós-graduação em Saúde Ambiental - Faculdade de Saúde Pública, Universidade de São Paulo, 2004.

${ }^{16}$ MATTOS, Rita de Cássia Oliveira da Costa et al. Avaliação dos fatores de risco relacionados à exposição ao chumbo em crianças e adolescentes do Rio de Janeiro. Ciênc. Saúde Coletiva, Rio de Janeiro, v. 14, n. 6, dez. 2009. 
Grosso modo, pode-se dizer que o contencioso envolvendo esse plexo de fatos possui, excluída a esfera administrativa, três frentes judiciais: (a) a comum ${ }^{17}$, (b) a trabalhista ${ }^{18}$ e (c) a fiscal, sendo a última o objeto deste comentário. Note-se que, a despeito da potencial repercussão do acórdão ora examinado em diversas disciplinas jurídicas, ele curiosamente é fruto da seara tributária.

Isso ocorre porque uma das respostas estatais aos danos causados pela Ajax foi o auto de infração da Vigilância Sanitária do Estado de São Paulo, que determinou a multa administrativa de $\mathrm{R} \$$ 65.950,00 como sanção pela emissão reiterada de chumbo na atmosfera, causando a exposição e a contaminação do meio ambiente e da população de baixa renda residente nas imediações da fábrica. Diante da inadimplência da empresa, restou à Procuradoria do Estado a execução fiscal da multa. No âmbito estadual, a ação teve como deslinde a denegação, pelo Tribunal de Justiça do Estado de São Paulo, dos embargos de declaração opostos pela Ajax. Inconformada, a Ajax interpôs um recurso especial junto ao STJ. Da data de aplicação da multa, em 20 de setembro de 2002, até o trânsito em julgado do acórdão ora em apreço, ao final de 2013, transcorreram, portanto, mais de 11 anos de processo judicial.

Entre os muitos argumentos suscitados pela Ajax para contestar a multa, o relator do processo no STJ, Ministro Herman Benjamin, teve de enfrentar o debate sobre o já citado padrão da OMS que estabelece os valores de referência para plumbemia.

\section{0 suposto conflito entre as normas interna e internacional}

Desde o início da mais aguda fase das denúncias, em 2002, a empresa Ajax argumentou junto à opinião pública, e em todas as suas peças de defesa administrativas e judiciais, que os índices máximos de chumbo no sangue propostos pela OMS não encontravam respaldo na legislação brasileira ${ }^{19}$. O inquérito conduzido pela

\footnotetext{
${ }^{17}$ Nela se destaca a ação civil pública ambiental proposta pelo Instituto Ambiental Vidágua em 21 de março de 2002 ( $4^{\text {a }}$ Vara Cível de Bauru, Processo n. 742/02). Mais de nove anos depois, um acordo entre as partes foi homologado pelo juiz, em 22 de julho de 2011, com a concoardância do Município de Bauru e do Ministério Público do Estado de São Paulo. Entre os pedidos formulados pela autora, encontravam-se a condenação da ré a promover a completa descontaminação da área atingida, pelos meios indicados por perícia técnica judicial; a indenizar as vítimas por danos morais; e a arcar com os custos de tratamento médico das pessoas contaminadas, indenizando inclusive o Sistema Único de Saúde (SUS) pelos serviços já prestados.

${ }^{18}$ Diante do descumprimento dos Termos de Ajustamento de Conduta (TACs), assinados em 2001 e 2002 , o Ministério Público do Trabalho ajuizou ação civil pública junto à Justiça do Trabalho de Bauru com o objetivo de sanar as irregularidades relativas à degradação do ambiente de trabalho na empresa e obter reparação pelos danos causados. O processo chegou ao Tribunal Superior do Trabalho (Processo n. $9024-$ 07-2006.5.15.0091). Em maio de 2012, a ação teria sido extinta por conciliação entre as partes, mediante o pagamento pela empresa de indenização no valor de $\mathrm{R} \$ 366$ mil, revertida a dez entidades beneficentes da região. AJAX terá de pagar R $\$ 366$ mil de indenização por contaminação de chumbo. Jornal da Cidade de Bauru - JCNET, Bauru, 23 mar. 2012.

${ }^{19}$ GREENPEACE. Crimes ambientais corporativos no Brasil, cit., p. 7.
} 
Polícia Civil local concluiu que não apenas faltavam provas materiais a respeito da intenção da empresa de contaminar o meio ambiente, mas também que os índices de tolerância ao chumbo no sangue humano eram controversos ${ }^{20}$.

Ao contrário do que costumam fazer os juízes brasileiros, inclusive nas mais altas instâncias da jurisdição pátria, o Ministro Benjamin recusou-se a investigar o processo de incorporação da referida norma no ordenamento jurídico brasileiro, tampouco buscou perscrutar a hierarquia entre normas internacionais e internas sobre a matéria. Evitou, ainda, dirimir eventual clivagem geral entre hard law e soft law.

Em seu voto unanimemente acolhido pela Segunda Turma do STJ, Benjamin entendeu que as instâncias ordinárias afastaram a tese da empresa, ao demonstrar a inexistência de índices nacionais para a plumbemia. Mas o relator foi além: na ausência de padrões na legislação brasileira, ou em caso de sua manifesta desatualização, a contaminação e o consequente dano se caracterizam quando se constata o desrespeito aos padrões considerados normais ou aceitáveis por instituições internacionais de renome e legitimidade das quais o Brasil seja membro ou partícipe.

Ocorreu, portanto, o que Mireille Delmas-Marty identifica como uma hipótese de "endurecimento" do direito "brando" ou "maleável" (soft law), que pode ocorrer quando o juiz nacional, por meio da aplicação judicial, é capaz de sancionar a violação da norma branda, articulando o conteúdo normativo do direito internacional à força coercitiva da ordem interna ${ }^{21}$.

Não se confunda tal decisão, porém, com o reconhecimento de um novo status jurídico geral para as normas internacionais no Brasil, que de modo algum se verifica. Como regra de solução de conflitos de normas, prevalece em nosso país o entendimento jurisprudencial da equivalência entre tratado internacional e lei interna, cujos eventuais conflitos são dirimidos pela via do primado da norma especial sobre a geral, assim como a prevalência da norma posterior sobre a anterior. A exceção a tal desígnio hierárquico é bem conhecida, e diz respeito aos tratados internacionais de direitos humanos aprovados por maioria qualificada pelo Congresso Nacional ${ }^{22}$.

\footnotetext{
${ }^{20}$ SALOMÃO, Virgínia. op. cit., p. 4.

${ }^{21}$ DELMAS-MARTY, Mireille. Résister, responsabiliser, anticiper. Paris: Seuil, 2013. p. 148.

${ }^{22}$ Conforme o artigo $5^{\circ}$, parágrafo $3^{\circ}$, da Constituição Federal de 1988 , originado na Emenda Constitucional n. 45/2004, "os tratados e convenções internacionais sobre direitos humanos que forem aprovados, em cada Casa do Congresso Nacional, em dois turnos, por três quintos dos votos dos respectivos membros, serão equivalentes às emendas constitucionais". (BRASIL. Constituição da República Federativa do Brasil de 1988. Disponível em: <http://www.planalto.gov.br/ccivil_03/constituicao/constituicaocompilado.htm>. Acesso em: 06 mar. 2015). 0 primeiro instrumento a se beneficiar do status de emenda constitucional foi a Convenção sobre os Direitos das Pessoas com Deficiência e seu Protocolo Facultativo, assinado em Nova lorque, em 30 de março de 2007, e promulgado no Brasil pelo Decreto n. 6.949/2009. (BRASIL. Decreto n. 6.949, de 25 de agosto de 2009. Promulga a Convenção Internacional sobre os Direitos das Pessoas com Deficiência e seu Protocolo Facultativo, assinados em Nova York, em 30 de março de 2007. Disponível em: <http://www.planalto.gov.br/ccivil_03/_ato2007-2010/2009/decreto/d6949.htm>. Acesso em: 06 mar. 2015).
} 
No que se refere à articulação entre o internacional e o interno, o relator limitou-se a afirmar que a legislação nacional é a principal, mas não a única referência para o juiz, eis que a Constituição Federal - por força da "ampla e inafastável proteção constitucional da saúde" - institui uma "cláusula geral implícita” de que seus padrões, critérios e parâmetros são simples pontos de partida para o juiz, devendo ser lidos à luz do que foi acordado pela comunidade científica internacional.

Na verdade, a única hierarquia estabelecida por esse acórdão é o princípio in dubio pro salute, que o relator aduz do artigo 196 da Constituição Federal, segundo o qual a saúde é um direito de todos e um dever do Estado. Tal dever traria ao Poder Judiciário a função de, "com olhos postos nos riscos e orientado preventiva ou precautoriamente", "evitar e mitigar danos, mormente os coletivos, intergeneracionais, e de difícil identificação, quantificação e reparação".

Em outras palavras, segundo o relator, o dever do juiz é o de fazer prevalecer a norma que melhor assegure a saúde, seja ela branda ou dotada de sanção, seja ela internacional ou interna. Sem a pretensão de resolver as relações entre governança (exercida especialmente pelas normas não coercitivas) e o direito tradicional, esse acórdão procura buscar nas diferentes esferas normativas a forma jurídica de consubstanciar na realidade o privilegiado status constitucional da saúde.

Do ponto de vista da responsabilidade dos Estados e das empresas por danos à saúde humana - especialmente a saúde dos hipossuficientes -, esse acórdão parece ser um passo importante. Ele reconhece no Poder Judiciário a capacidade de suprir eventuais falhas de uma ordem jurídica nacional complacente com as empresas cuja atuação predatória impinge danos sanitários desigualmente distribuídos, graças ao recurso a padrões internacionais mais protetivos.

Finalmente, por melhores auspícios que suscite essa bela sentença, deve ser destacado o tanto que o Brasil ainda tem por fazer em matéria de responsabilidade das empresas por danos sanitários e ambientais. O próprio relator destaca a ineficiência do sistema sancionatório administrativo relativo às infrações sanitárias, e ao poder de polícia do Estado de maneira geral. Tão aberto ao internacionalismo econômico e comercial, nosso país é acometido de evidente provincianismo jurídico em relação à aplicação judicial das normas internacionais de direitos humanos.

O Brasil só teria a ganhar ao fomentar o diálogo entre ordens e juízes das mais diversas esferas: internacional, regional, comparada, local etc. Sob pena de se assemelhar - o Estado, e não somente a empresa - ao Ajax da tragédia de Sófocles, que um dia, ao despertar da loucura, vê-se devastado pela insuportável consciência da chacina que praticou ${ }^{23}$.

23 “No caso da loucura de Ajax, operada pela intervenção de Atena, os intuitos de vingança do herói sobre os Atri-
das e Ulisses, por Ihe não terem sido atribuídas as armas de Aquiles em benefício do rei de Ítaca, são frustrados
pela deusa que, no momento em que a vindicta estava a ponto de ser executada, faz descer sobre os olhos do
herói um conhecimento enganador e o leva a chacinar as reses do exército, pensando assassinar os chefes dos
Aqueus”. FIALHO, Maria do Ceú. A pedagogia pela loucura no Ajax de Sófocles. Humanitas, v. 47, p. 104, 1995. 


\section{Referências}

AJAX terá de pagar R 366 mil de indenização por contaminação de chumbo. Jornal da Cidade de Bauru - JCNET, Bauru, 23 mar. 2012.

DASCANIO, Denise, Crianças e adolescentes com plumbemia: habilidades sociais, funcionamento intelectual e problemas de comportamento. Tese (Doutorado) - Programa de Pós-graduação em Psicologia - Centro de Educação, Universidade Federal de São Carlos, 2012.

; VALLE, Tania Gracy Martins do. A associação entre variáveis sócio-demográficas e plumbemia em crianças. Paidéia, Ribeirão Preto, v. 18, n. 4, dez. 2008.

DELMAS-MARTY, Mireille. Résister, responsabiliser, anticiper. Paris: Seuil, 2013.

FIALHO, Maria do Ceú. A pedagogia pela loucura no Ajax de Sófocles. Humanitas, v. 47, 1995.

FREITAS, Clarice. Vigilância de população exposta a chumbo no município de Bauru - São Paulo: investigação de fatores de risco de exposição e avaliação da dinâmica institucional. Tese (Doutorado) - Programa de Pós-graduação em Saúde Ambiental - Faculdade de Saúde Pública, Universidade de São Paulo, 2004.

GOSTIN, Lawrence. Global health law. Cambridge; Londres: Harvard University Press, 2014.

GREENPEACE. Crimes ambientais corporativos no Brasil. jun. 2002. Disponível em: <http:// www.greenpeace.org.br/toxicos/pdf/corporate_crimes_port.pdf >. Acesso em: 26 jul. 2014.

HERMITTE, Marie-Angèle. Le droit saisi au vif - Sciences, Technologie, formes de vie. Paris: Pétra, 2013.

ITANI, Alice et al. Debate em gestão integrada em saúde e meio ambiente: fatos emblemáticos. Interfacehs - Revista de Gestão Integrada e Saúde do Trabalho e Meio Ambiente, v. 3, n. 2, abr./ago. 2008 .

MATTOS, Rita de Cássia Oliveira da Costa et al. Avaliação dos fatores de risco relacionados à exposição ao chumbo em crianças e adolescentes do Rio de Janeiro. Ciênc. Saúde Coletiva, Rio de Janeiro, v. 14, n. 6, dez. 2009.

PADULA, Niura et al. Intoxicação por chumbo e saúde infantil: ações intersetoriais para o enfrentamento da questão. Cad. Saúde Pública, Rio de Janeiro, v. 22, n. 1, jan. 2006.

SALOMÃO, Virgínia. Empresa ou imprensa vilã? Caso de contaminação por chumbo na cidade de Bauru reafirma antigas deficiências na responsabilidade social corporativa. In: CONGRESSO VIRTUAL DE COMUNICAÇÃO EMPRESARIAL, 1. 2004. Disponível em: $<$ http://www.comtexto.com.br>. Acesso em: 26 jul. 2014. 
Deisy de Freitas Lima Ventura - Doutora em Direito Internacional e Mestre em Direito Comunitário e Europeu pela Universidade de Paris 1, Panthéon-Sorbonne; Graduada em Direito e Mestre em Integração Latino-Americana pela Universidade Federal de Santa Maria. Professora de Direito Internacional e Livre-Docente do Instituto de Relações Internacionais da Universidade de São Paulo; Professora do Doutorado em Saúde Global e Sustentabilidade da Faculdade de Saúde Pública da Universidade de São Paulo. Membro do Núcleo de Pesquisa em Direito Sanitário da Universidade de São Paulo. São Paulo/SP, Brasil. Blog: http://saudeglobal.org/. Twitter: http://twitter.com/Deisy_Ventura.

Rachelle Amália Agostini Balbinot - Graduada em Direito pela Universidade Federal de Santa Maria; Mestre em Direito pela Universidade Federal de Santa Catarina; Doutora em Integração da América Latina pela Universidade de São Paulo; Pós-Doutora em Saúde Pública pela Faculdade de Saúde Pública da Universidade de São Paulo. Vice-Diretora e pesquisadora do Centro de Estudos e Pesquisas em Direito Sanitário; Pesquisadora do Núcleo de Pesquisa em Direito Sanitário da Universidade de São Paulo. Advogada. São Paulo/SP, Brasil. E-mail: rachelle@usp.br. 